\title{
Guidelines for mono, double and triple antithrombotic therapy
}

\author{
Renate C A E van Uden, ${ }^{1,2}$ Ilse Houtenbos, ${ }^{3}$ Anita Griffioen-Keijzer, ${ }^{3}$ \\ Diego A M Odekerken, ${ }^{4}$ Patricia M L A van den Bemt, ${ }^{5}$ Matthijs L Becker (1) ${ }^{1,2}$
}

${ }^{1}$ Hospital Pharmacy, Spaarne Gasthuis, Haarlem, NoordHolland, Netherlands ${ }^{2}$ Pharmacy Foundation of Haarlem Hospitals, Haarlem, Noord-Holland, Netherlands ${ }^{3}$ Internal Medicine, Spaarne Gasthuis, Haarlem, NoordHolland, Netherlands ${ }^{4}$ Cardiology, Spaarne Gasthuis Hospital, Haarlem, NoordHolland, Netherlands

${ }^{5}$ Clinical Pharmacy and Pharmacology, Universitair Medisch Centrum Groningen, Groningen, Groningen, Netherlands

\section{Correspondence to} Dr Matthijs L Becker, Hospital Pharmacy, Spaarne Gasthuis, Haarlem, Noord-Holland, Netherlands; mbecker@sahz.nl

Received 25 August 2020 Revised 13 November 2020 Accepted 23 November 2020 Published Online First 13 January 2021

Check for updates

(C) Author(s) (or their employer(s)) 2021. No commercial re-use. See rights and permissions. Published by BMJ.

To cite: van Uden RCAE, Houtenbos I, Griffioen-Keiizer A, et al. Postgrad Med J 2021:97:730-737

\section{ABSTRACT}

Guidelines for antithrombotic therapy are complex, especially if a patient has several indications that require antithrombotic therapy. In general, no patient should receive lifelong double or triple antithrombotic therapy. In this overview, we outline the most common indications for mono, double and triple antithrombotic therapy; the preferred antithrombotic therapy and the recommended duration of therapy. Both antiplatelet therapy and therapeutic anticoagulation therapy with vitamin $\mathrm{K}$ antagonists or direct oral anticoagulants were included. European guidelines were used or, if no European guidelines were available, the Dutch guidelines were used.

\section{INTRODUCTION}

Antithrombotics are indicated for multiple indications and are prescribed by almost all medical specialties. They are intended to lower the risk of thrombosis, but generally at the cost of increasing the risk of haemorrhage. A substantial number of patients use two or more antithrombotics ${ }^{1-3}$; however, combining two or three antithrombotics increases the bleeding risk twofold to fourfold compared with monotherapy. ${ }^{4-6}$ Treatment schedules in guidelines are complex, especially if a patient has several indications that require multiple antithrombotics. ${ }^{7-18}$ Guidelines advise using combinations of antithrombotics for a limited period of time. Yet, due to the complexity of the guidelines, the combination may be inadvertently used too long. ${ }^{7-18}$ A study by Warlé-Van Herwaarden et al. showed that $14 \%-23 \%$ of the patients in a community pharmacy who used double antithrombotic therapy did not have an indication for the prescribed therapy anymore. ${ }^{19}$ The 'Hospital Admissions Related to Medication' study showed that antithrombotic drugs are often associated with preventable hospital admissions. ${ }^{20}$

It is important for healthcare providers to be familiar with the guidelines for antithrombotic therapy. This article aims to provide an overview of the indications for mono, double and triple antithrombotic therapy; the preferred antithrombotic therapy and the recommended duration of the therapy. The guidelines for the non-acute treatment with antithrombotics are presented. With the information in this overview, healthcare providers can assess whether the prescribed antithrombotic therapy for a patient is adequate or whether the medication should be adjusted.

\section{BACKGROUND OF THROMBOSIS}

Formation of a thrombus is a complex physiological process caused by multiple factors. Three factors together known as Virchow's triad are important in the pathophysiology of thrombosis: damage to the endothelial lining of the vessel wall, a hypercoagulable state and stasis of blood flow. ${ }^{21}$

\section{Venous thrombosis}

Venous thrombi develop in veins, especially in areas with a diminished blood flow, for instance, around vein valves. These valves promote blood flow through the venous system, but are also a potential location for venous stasis. Venous thrombi consist of fibrin and can cause venous thromboembolism, that is, deep venous thrombosis or a pulmonary embolism. ${ }^{21}$ Low-molecular-weight heparins (LMWHs), vitamin $\mathrm{K}$ antagonists (VKAs) or direct oral anticoagulants (DOACs), are used for the prevention and treatment of venous thrombosis. VKAs and DOACs are part of the group of oral anticoagulants (OAC). LMWHs inhibit coagulant factor II and X and are mostly used temporarily, for instance, for bridging VKA therapy or as a temporary replacement for a VKA or DOAC. VKAs inhibit the carboxylation of vitamin K-dependent coagulation factors II, VII, IX and $\mathrm{X}$ in the liver and inhibit the coagulation process indirectly. The DOACs apixaban, edoxaban and rivaroxaban inhibit activated coagulation factor X. The inhibition of factor Xa interrupts the intrinsic and extrinsic routes of the coagulation cascade. The DOAC dabigatran inhibits activated factor II (thrombin) and prevents the conversion of fibrinogen to fibrin and prevents the formation of thrombi. ${ }^{22}$

\section{Arterial thrombosis}

Plaque formation in the arterial wall is the initiating factor for the occurrence of arterial thrombosis. Arterial thrombi consist mostly of thrombocytes. Therefore, antiplatelet therapy is indicated for the prevention of arterial thrombosis. Acetylsalicylic acid (ASA) inhibits the synthesis of thromboxane $A_{2}$ in thrombocytes by acetylating cyclo-oxygenase 1 , thus inhibiting thrombocyte aggregation. Carbasalate calcium is the calcium salt of ASA and is not mentioned separately in this article. P2Y12 inhibitors such as clopidogrel, ticagrelor and prasugrel inhibit the P2Y12-ADP receptor on the surface of thrombocytes, causing the inhibition of thrombocyte aggregation. ${ }^{22}$ Arterial thrombosis may lead to an acute coronary syndrome (ACS), peripheral 
Table 1 Single antiplatelet therapy Single antiplatelet therapy (SAPT)

\begin{tabular}{|c|c|c|c|}
\hline Indication & Therapy & $\begin{array}{l}\text { Duration of } \\
\text { therapy }\end{array}$ & Guideline \\
\hline $\begin{array}{l}\text { Cerebrovascular accident } \\
\text { or Transient Ischaemic } \\
\text { Attack }>21 \text { days ago }\end{array}$ & $\begin{array}{l}\text { First-choice: } \\
\text { Clopidogrel }^{*} \\
\text { Second choice: ASA } \\
\text { +dipyridamole } \\
\text { Third choice: ASA }\end{array}$ & Lifelong* & $\begin{array}{l}2019 \text { FMS Herseninfarct en hersenbloeding } \\
\text { (Cerebral infarction and cerebral haemorrhage) }\end{array}$ \\
\hline $\begin{array}{l}\text { Coronary artery disease/ } \\
\text { Stable Angina }\end{array}$ & ASA & Lifelong* & 2013 ESC Guidelines on the management of stable coronary artery disease ${ }^{8}$ \\
\hline $\begin{array}{l}\text { Acute coronary syndrome } \\
\text { or } \mathrm{PCl}>1 \text { year }\end{array}$ & Clopidogrel or ASA & Lifelong* & 2017 ESC focused update on dual antiplatelet therapy in coronary artery disease ${ }^{9}$ \\
\hline $\begin{array}{l}\text { CABG in stable CAD } \\
\text { setting }\end{array}$ & Clopidogrel or ASA & Lifelong* & 2017 ESC focused update on dual antiplatelet therapy in coronary artery disease ${ }^{9}$ \\
\hline $\begin{array}{l}\text { TAVI procedure with high } \\
\text { bleeding risk }\end{array}$ & Clopidogrel or ASA & Lifelong* & 2017 ESC/EACTS Guidelines for the management of valvular heart disease ${ }^{10}$ \\
\hline $\begin{array}{l}\text { TAVI procedure }>3-6 \\
\text { months ago }\end{array}$ & Clopidogrel or ASA & Lifelong* & 2017 ESC/EACTS Guidelines for the management of valvular heart disease ${ }^{10}$ \\
\hline $\begin{array}{l}\text { Aortic bioprosthesis or } \\
\text { valve sparing surgery }\end{array}$ & ASA & 3 months & 2017 ESC/EACTS Guidelines for the management of valvular heart disease ${ }^{10}$ \\
\hline $\begin{array}{l}\text { Surgical implantation } \\
\text { of a mitral or tricuspid } \\
\text { bioprothesis } \\
>3 \text { months ago }\end{array}$ & ASA & Lifelong* & 2017 ESC/EACTS Guidelines for the management of valvular heart disease ${ }^{10}$ \\
\hline $\begin{array}{l}\text { Surgical mitral or tricuspid } \\
\text { valve repair } \\
>3 \text { months ago }\end{array}$ & ASA & Lifelong* & 2017 ESC/EACTS Guidelines for the management of valvular heart disease ${ }^{10}$ \\
\hline Peripheral arterial disease & Clopidogrel or ASA & Lifelong* & 2017 ESVS/ESC Guidelines on the diagnosis and treatment of peripheral arterial diseases ${ }^{11,12}$ \\
\hline Carotid stenosis & Clopidogrel or ASA & Lifelong* & $\begin{array}{l}2019 \text { FMS Herseninfarct en hersenbloeding } \\
\text { (Cerebral infarction and cerebral haemorrhage) }\end{array}$ \\
\hline $\begin{array}{l}\text { Carotid stenosis stenting } \\
>6 \text { months ago }\end{array}$ & Clopidogrel or ASA & Lifelong* & 2017 ESVS/ESC Guidelines on the diagnosis and treatment of peripheral arterial diseases ${ }^{11,12}$ \\
\hline $\begin{array}{l}\text { Peripheral percutaneous } \\
\text { revascularisation } \\
>1 \text { month ago }\end{array}$ & Clopidogrel or ASA & Lifelong* & 2017 ESVS/ESC Guidelines on the diagnosis and treatment of peripheral arterial diseases ${ }^{11,12}$ \\
\hline $\begin{array}{l}\text { Below the knee bypass } \\
\text { with prosthetic graft } \\
>1 \text { year ago }\end{array}$ & Clopidogrel or ASA & Lifelong* & 2017 ESVS/ESC Guidelines on the diagnosis and treatment of peripheral arterial diseases ${ }^{11,12}$ \\
\hline Venous bypass & Clopidogrel or ASA & Lifelong* & 2017 ESVS/ESC Guidelines on the diagnosis and treatment of peripheral arterial diseases ${ }^{11,12}$ \\
\hline
\end{tabular}

arterial diseases (PAD), a transient ischaemic attack (TIA) or a cerebrovascular accident (CVA).

\section{Types and combinations of antithrombotic therapy}

Antithrombotic therapy can be divided into several classes depending on the number and class of drugs used. Single antiplatelet therapy (SAPT) is therapy with one platelet inhibitor, and dual antiplatelet therapy (DAPT) is therapy with two platelet inhibitors. Double therapy consists of one platelet inhibitor and an OAC, and triple therapy consists of DAPT with an OAC. The bleeding risk increases with the number of antithrombotics. ${ }^{4-6}$ A Danish study found that the incidence of major bleedings per 100 patient-years was 2.6 for SAPT, 2.3 for OAC, 3.8 for DAPT, 4.7 for double therapy and 10.2 for patients using triple therapy. ${ }^{6}$

\section{Risk stratification}

The antithrombotic regimen should be tailored based on the patients' ischaemic and bleeding risk profile. Depending on the indication, several tools were developed to assess the bleeding and ischaemic risk. The $\mathrm{CHA}_{2} \mathrm{DS}_{2}$-VASc score can be calculated to estimate the risk of stroke in patients with atrial fibrillation. Patients without clinical stroke risk factors do not need an OAC while patients with stroke risk factors that is, $\mathrm{CHA}_{2} \mathrm{DS}_{2}-\mathrm{VASc}$ score of $\geq 1$ or more for men and $\geq 2$ or more for women, are likely to benefit from an OAC. ${ }^{23}$

The HAS-BLED score is a scoring system developed to assess the risk of major bleeding in patients using a VKA for atrial fibrillation. ${ }^{14}$ The HAS-BLED score can be used to identify treatable factors, such as hypertension. ${ }^{14}$

The bleeding risk in patients at the time of percutaneous coronary intervention (PCI) can be assessed using the Academic Research Consortium for High Bleeding Risk tool or using the PRECISE-DAPT score. ${ }^{18}$ In patients with a high bleeding risk, a shorter duration of DAPT may be considered, while in patients with a lower bleeding risk standard duration of DAPT may be considered. ${ }^{18}$ After 12 months of uneventful treatment, the DAPT score can be calculated and might be helpful to consider whether treatment with DAPT should be prolonged after 12 months. The PRECISE-DAPT score and the DAPT score are different risk scores and are calculated by 
Table 2 Dual antiplatelet therapy (DAPT)

\begin{tabular}{|c|c|c|c|}
\hline Indication & Therapy & Duration of therapy & Guideline \\
\hline $\begin{array}{l}\text { Minor non-cardioembolic ischaemic stroke } \\
<21 \text { days ago, who did not receive IV } \\
\text { alteplase }\end{array}$ & Clopidogrel+ASA & 21 days, followed by lifelong clopidogrel ${ }^{*}$. & $\begin{array}{l}2019 \text { FMS Herseninfarct en hersenbloeding } \\
\text { (Cerebral infarction and cerebral haemorrhage) }\end{array}$ \\
\hline $\begin{array}{l}\text { Acute coronary syndrome (NSTEMI, STEMI, } \\
\text { iAP) }\end{array}$ & $\begin{array}{l}\text { DAPT } \dagger \\
\text { (ASA+P2Y12 inhibitor) }\end{array}$ & $\begin{array}{l}\text { 3-36 months }{ }^{\dagger} \\
\text { In general } 12 \text { months, followed by lifelong } \\
\text { SAP** }\end{array}$ & $\begin{array}{l}2017 \text { ESC focused update on dual antiplatelet therapy } \\
\text { coronary artery disease }{ }^{9}\end{array}$ \\
\hline
\end{tabular}

\begin{tabular}{ll} 
PCl in stable CAD setting & Clopidogrel+ASA \\
TAVI (without high bleeding risk) & Clopidogrel+ASA \\
Below the knee bypass with a prosthetic graft & Clopidogrel+ASA \\
\hline Carotid artery stenting & Clopidogrel+ASA
\end{tabular}

Revascularisation percutaneous in patients Clopidogrel+ASA with lower extremity artery disease Infra-inguinal stent implementation

\section{$1-30$ months $\ddagger$}

In general 6 months followed by lifelong

SAPT*

3-6 months after, TAVI. Followed by lifelong SAPT*.

At least 1 year. Not clearly indicated in guideline for which period. Followed by SAPT*.

At least 1 month, optimal duration is not known. In studies/research setting till 6 months. Followed by lifelong SAPT*

At least 1 month, in research setting till 12 months. Followed by lifelong SAPT*

* Lifelong indication, unless patients develop an indication for a therapeutic anticoagulation therapy. In these cases, the antithrombotic therapy for patients must be evaluated in terms of whether antiplatelet therapy is still indicated.

tDepending on indication and treatment choice (medically managed, PCI or CABG, bleeding risk, PRECISE-DAPT score or DAPT score. (2017 ESC focused update on dual antiplatelet therapy in coronary artery disease). ${ }^{13}$

‡Depending on bleeding risk (PRECISE-DAPT).

ASA, acetylsalicylic acid; CABG, coronary artery bypass grafting; CAD, coronary artery disease; EACTS, European Society of Cardio-Thoracic Surgery; ESC, European Society of Cardiology; ESVS, European Society of Vascular Surgery; FMS, Federation of Medical Specialists; iAP, instable angina pectoris; NSTEMI, non-ST-segment elevation myocardial infarction; $\mathrm{PCl}$, percutaneous coronary intervention; TAVI, transcatheter aortic valve implantation.

different risk factors. For instance, the DAPT score includes myocardial infarction at presentation, smoking status and diabetes mellitus. Whereas the PRECISE-DAPT score does not include these factors, but includes for instance renal function and prior bleeding. ${ }^{18}$

Klok and Huisman describe the different risk stratification schemes for major bleeding in patients with venous thromboembolism (VTE). ${ }^{24}$ The ACCP risk table, the VTE-BLEED, RIETE and HAS-BLED could be used in patients with a VTE. Klok and Huisman advise to screen for modifiable and treatable risk factors for major bleeding, for instance, hypertension and drug adherence. They also advise to identify patients with a low bleeding risk in whom long-term treatment with an OAC should be considered. ${ }^{24}$

\section{Racial differences}

Ethnicity-related differences should be considered when starting antithrombotic therapy. The concept of the East Asian paradox states that East Asian patients have a lower risk of thrombosis and a higher risk of bleeding. ${ }^{25}$ Therefore, a different target of the international normalised ratio (INR) in East Asians has been proposed for treating non-valvular atrial fibrillation (INR 1.6-2.6) compared with the European Guidelines (INR 2.0-3.0). ${ }^{27}$ When comparing patients with a similar INR range, more intracranial bleedings occurred in the East Asian population compared with the Caucasian population. ${ }^{28}$ Considering the increased bleeding risk the advised dose of the platelet inhibitor prasugrel in Japanese guidelines is $3.75 \mathrm{mg}$ once daily compared with $10 \mathrm{mg}$ once daily in Western guidelines. ${ }^{29}$ The advised

Table 3 Therapeutic anticoagulation therapy (OAC)

\begin{tabular}{|c|c|c|c|}
\hline Indication & Therapy & Duration of therapy & Guideline \\
\hline $\begin{array}{l}\text { Non-valvular atrial fibrillation or atrial } \\
\text { flutter with } \mathrm{CHA}_{2} \mathrm{DS}_{2}-\mathrm{VASC} \geq 2\end{array}$ & DOAC or VKA & Lifelong & 2016 ESC Guidelines for the management of atrial fibrillation. ${ }^{14}$ \\
\hline $\begin{array}{l}\text { Atrial fibrillation }>48 \text { hours existing for } \\
\text { which cardioversion is indicated and } \\
\mathrm{CHA}_{2} \mathrm{DS}_{2}-\mathrm{VASC}<2\end{array}$ & DOAC or VKA & $\begin{array}{l}\text { At least } 3 \text { weeks prior to } \\
\text { cardioversion until } 4 \text { week after } \\
\text { cardioversion }\end{array}$ & 2016 ESC Guidelines for the management of atrial fibrillation. ${ }^{14}$ \\
\hline Venous thromboembolism & DOAC or VKA & 3 months to lifelong & $\begin{array}{l}2016 \text { FMS Antithrombotisch beleid } \\
\text { (Antithrombotic policy) } \\
2019 \text { ESC Guidelines for the diagnosis and management of acute pulmonary } \\
\text { embolism developed in collaboration with the European } \\
\text { Respiratory Society. }{ }^{16}\end{array}$ \\
\hline Mechanical valve & VKA & Lifelong & 2017 ESC Guidelines for the management of valvular heart disease. ${ }^{12}$ \\
\hline $\begin{array}{l}\text { Biological mitral of tricuspidal valve }<3 \\
\text { months (implantation or reconstruction) }\end{array}$ & VKA & $\begin{array}{l}3 \text { months, followed by lifelong } \\
\text { SAPT }\end{array}$ & 2017 ESC/EACTS Guidelines for the management of valvular heart disease. ${ }^{10}$ \\
\hline
\end{tabular}

EACTS, European Society of Cardio-Thoracic Surgery; ESC, European Society of Cardiology; FMS, Federatie Medisch Specialisten; VKA, vitamin K antagonists. 
duration of DAPT for an ACS in Japanese guidelines is shorter compared with the Western guidelines. ${ }^{29}$ Mak et al. showed that the cardiovascular and all-cause mortality in patients with coronary artery disease (CAD), PAD or CVA treated with antiplatelet therapy was significantly higher among African American patients when compared with Asian patients. ${ }^{30}$ Therefore, antithrombotic therapy is not a one-size-fits-all strategy, but should be tailored based on risk factors and ethnicity-related differences.

\section{Guidelines}

Tables 1-5 provide an overview of the most common indications for mono, double and triple antithrombotic therapy; the preferred antithrombotic therapy; and the recommended duration of the therapy. We used the European guidelines or, if no European guidelines were available, the Dutch guidelines were used. Figure 1 provides an overview of combinations of antithrombotic therapy. Physicians can intentionally deviate from guidelines, for instance, if patients have a high bleeding risk or a high ischaemic risk, or if patients have recurrent thrombotic events, while using recommended antithrombotic therapy.

When prescribing antithrombotic therapy several important issues should be taken into account.

In patients with non-valvular atrial fibrillation, treatment with an OAC is indicated in patients with a $\mathrm{CHA}_{2} \mathrm{DS}_{2}-\mathrm{VASc}$ stroke score of $\geq 1$ in males or $\geq 2$ in females. Patients with a mechanical valve should not receive a DOAC, but always a VKA, since patients with a DOAC for a mechanical heart valve had an increased thromboembolic and bleeding risk compared with patients treated with warfarin. ${ }^{10}{ }^{31}$ After a VTE, the treatment duration depends on whether the VTE was provoked or unprovoked and on additional risk factors. In patients with a non-ST-elevation myocardial infarction (NSTEMI) or ST-elevation myocardial infarction (STEMI), the optimal duration (and combination) of DAPT is not yet known. The duration depends on both the ischaemic and bleeding risk of the patient and if a patient uses an OAC. After a CVA short term DAPT should be prescribed. The preferred platelet inhibitor for CVA after short term DAPT is clopidogrel. A patient, who used ASA before a CVA, should receive 21 days of DAPT and should continue with only clopidogrel afterwards.

Most importantly, antithrombotic therapy is not a one-sizefits-all strategy but should be tailored based on risk factors and ethnicity-related differences.

\section{FUTURE DIRECTIONS}

Antithrombotic therapy is a moving target. A lot of studies are now being conducted to find the optimal antithrombotic regimen for various indications. We will highlight the results of three recently published trials of which the results have not been adopted yet in the guidelines, but are expected to be so in due time.

The COMPASS trial was a double-blind randomised clinical trial in 27000 patients with stable atherosclerotic vascular disease (CAD and/or PAD). ${ }^{32}$ Patients were randomised to receive either rivaroxaban two times a day $2.5 \mathrm{mg}$ in combination with ASA $100 \mathrm{mg}$, rivaroxaban two times a day $5 \mathrm{mg}$ or ASA $100 \mathrm{mg}$. The primary outcome was a composite of cardiovascular death, stroke or myocardial infarction. The primary outcome occurred significantly less in patients in the rivaroxaban plus ASA group (4.1\%) compared with the ASA group (5.4\%). There was no statistical significant difference between the rivaroxaban monotherapy group (4.9\%) and the ASA monotherapy group (5.4\%). 


\begin{tabular}{|c|c|c|c|}
\hline Indication & Therapy & Duration of triple therapy & Guideline \\
\hline $\begin{array}{l}\text { Indication for } \\
\text { therapeutic } \\
\text { anticoagulation } \\
\text { and } \mathrm{PCl} \\
<1 \text { month }\end{array}$ & $\begin{array}{l}\text { OAC+ASA+ } \\
\text { clopidogrel }\end{array}$ & $\begin{array}{l}1 \text { month after } \mathrm{PCI}^{*} \\
\text { Followed by OAC+SAPT for } 12 \text { months after PCI, followed by OAC } \\
\text { therapy lifelong }{ }^{+}\end{array}$ & $\begin{array}{l}2017 \text { ESC focused update on dual antiplatelet therapy in coronary artery } \\
\text { disease. }{ }^{9}\end{array}$ \\
\hline $\begin{array}{l}\text { Atrial } \\
\text { fibrillation, } \\
\text { NSTEMI and } \\
\mathrm{PCl}<1 \text { week }\end{array}$ & $\begin{array}{l}\text { OAC+ASA+ } \\
\text { clopidogrel }\end{array}$ & $\begin{array}{l}1 \text { week after PCI } \\
\text { Followed by OAC+SAPT for } 12 \text { months after PCI, followed by OAC } \\
\text { therapy lifelong } \dagger\end{array}$ & $\begin{array}{l}2020 \text { ESC Guidelines for the management of acute coronary syndromes in } \\
\text { patients presenting without persistent ST-segment elevation. }{ }^{18}\end{array}$ \\
\hline
\end{tabular}

*Longer duration till 6 months can be considered in patients with a high ischaemic risk or patients with a mechanical valve.

tUnless the therapeutic anticoagulation therapy is stopped, in which case ASA or clopidogrel should be started.

¥Longer duration till 1 month can be considered in patients with a high ischaemic risk.

ACS, acute coronary syndrome; ASA, acetylsalicylic acid; ESC, European Society of Cardiology; NSTEMI, non-ST-elevation myocardial infarction; OAC, oral anticoagulant; PCI,

percutaneous coronary intervention; SAPT, single antiplatelet therapy.

In the rivaroxaban plus ASA group significantly more major bleedings occurred (3.1\%) compared with the ASA monotherapy group (1.9\%). Rivaroxaban two times a day $2.5 \mathrm{mg}$ in combination with ASA is currently registered for prevention of atherothrombotic complications in patients with CAD and in patients with symptomatic PAD.

The TWILIGHT trial was a double-blind randomised clinical trial in 7119 post-PCI patients at high risk for bleeding or ischaemic events. ${ }^{33}$ These patients received DAPT (ticagrelor plus ASA) for 3 months and were then randomised to receive ticagrelor or ticagrelor plus ASA. In the ticagrelor alone group significantly less bleeding events occurred (4.0\%) than in the ticagrelor plus ASA group (7.1\%). There was no difference in ischaemic end points (3.9\% for both groups).

The POPular Genetics trial was a randomised clinical trial in PCI patients in which patients were randomised to a genotypeguided strategy for selection of a P2Y12 inhibitor or standard treatment with ticagrelor or prasugrel. ${ }^{34}$ Patients with a genetic variation in CYP2C19*2 and CYP2C19*3 received ticagrelor or prasugrel, because in these patients clopidogrel is probably less effective. Patients without a genetic variation of CYP2C19 received clopidogrel. Over 2400 patients were included. In the

\begin{tabular}{|c|}
\hline CVA or TIA \\
\hline ACS $^{1}$ \\
\hline
\end{tabular}

\begin{tabular}{c}
\hline $\mathrm{PCl}$ in stable $\mathrm{CAD}^{2}$ \\
\hline $\mathrm{TAVI}^{3}$ \\
\hline
\end{tabular}

Revascularization $\mathrm{PAD}^{4}$

\begin{tabular}{|c|}
\hline $\begin{array}{c}\text { Indication } \mathrm{OAC} \text { and } \\
\mathrm{ACS} / \mathrm{PCl}<1 \text { year }^{5}\end{array}$ \\
\hline $\begin{array}{c}\text { Indication OAC and } \mathrm{PCl} \\
<1 \text { month }^{6}\end{array}$ \\
\hline
\end{tabular}

\section{Clopidogrel}

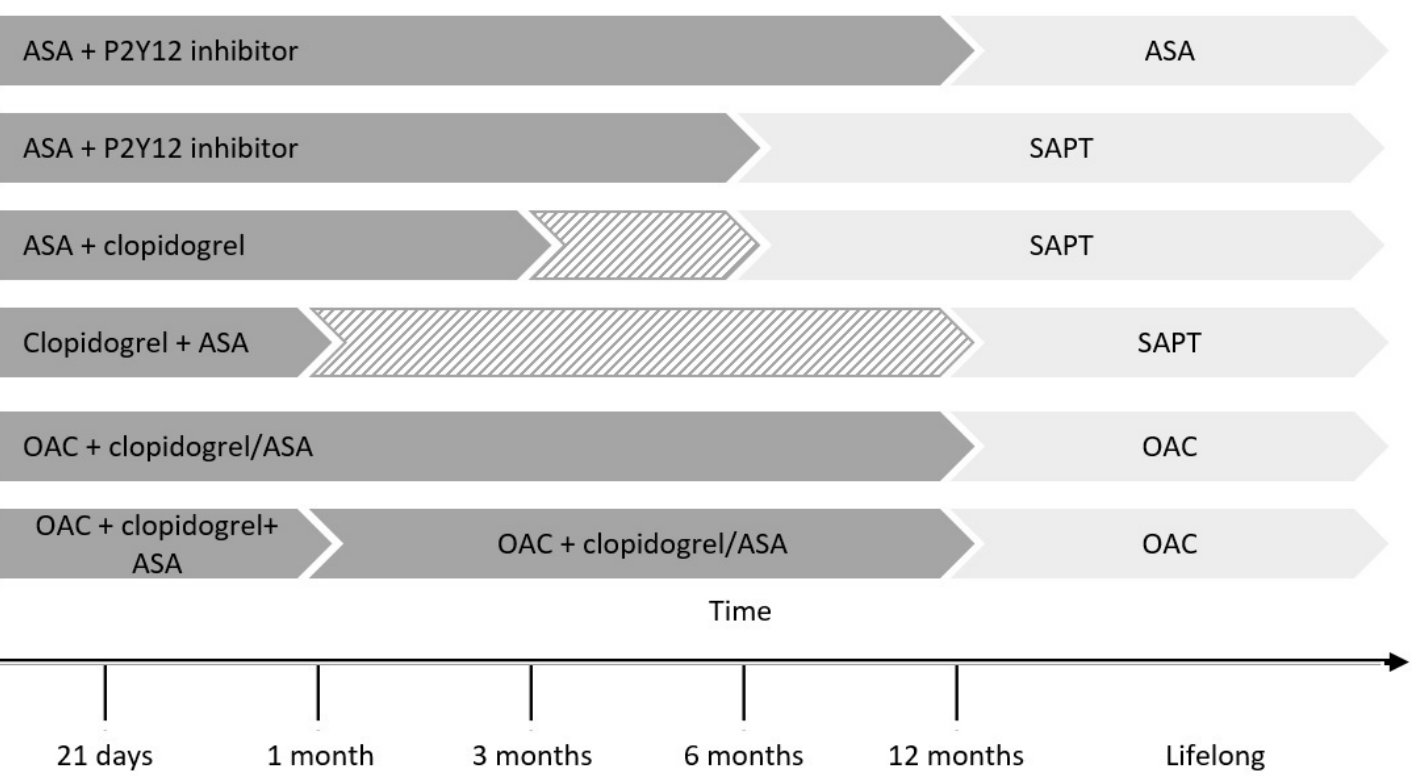

Figure 1 Combinations of antithrombotic therapy (1) DAPT duration 3-36 months, in general 12 months, duration depends on indication and treatment choice (medically managed, PCI or CABG, ischaemic and bleeding risk, PRECISE-DAPT score or DAPT score. (2) DAPT duration 1-30 months, in general 6 months, duration depends on ischaemic and bleeding risk (PRECISE-DAPT score). (3) DAPT duration in TAVI patients without a high bleeding risk 3-6 months. (4) DAPT duration at least 1 month, in research setting till 12 months after revascularization in PAD patients. (5) Duration of double therapy in general 12 months. Treatment can be extended in patients at very high risk of coronary events and in patients with mechanical prosthesis and atherosclerotic disease. Shorter duration may be considered in patients with a high bleeding risk. (6) Duration of triple therapy in general 1 month, longer duration till 6 months can be considered in patients with a high ischaemic risk or patients with a mechanical valve. In patients with atrial fibrillation and a NSTEMI the duration of triple therapy is one week. ACS, acute coronary syndrome; ASA, acetylsalicylic acid; CABG, coronary artery bypass grafting; CAD, coronary artery disease; CVA, cerebrovascular accident; DAPT, dual antiplatelet therapy; NSTEMI, nonST-elevation myocardial infarction; OAC, oral anticoagulants; PAD, peripheral arterial disease; PCl, percutaneous coronary intervention; SAPT, single antiplatelet therapy; TAVI, transcatheter aortic valve implantation. 
genotype-based group, the occurrence of thrombotic events was comparable $(5.1 \%)$ with the standard treatment group $(5.9 \%)$ and in the genotype-based group significant less bleeding events occurred $(9.8 \%)$ compared with the standard treatment group $(12.5 \%)$.

\section{Advice for daily practice}

When is double therapy indicated?

Double therapy is indicated, if a patient should be treated with an OAC and has had an acute coronary event or PCI in the past year. Other indications are a recent aortic bioprosthesis or valve sparing surgery less than 3 months or transcatheter aortic valve implantation (TAVI) less than 3-6 months ago; or having an indication for an OAC and with recent stenting of the carotid artery or endovascular revascularisation (table 4).

\section{When is triple therapy indicated?}

Triple therapy is indicated, if a patient should be treated with a therapeutic anticoagulation therapy and has had a PCI in the past week in case of an NSTEMI and a month in case of STEMI. If patients have a high bleeding risk, a physician can choose to give double therapy instead of triple therapy. During the period of double or triple therapy, a physician can consider to reduce the dosage of rivaroxaban to $15 \mathrm{mg}$ every day and the dosage of dabigatran to $110 \mathrm{mg}$ two times a day or target the INR in the lower part of the recommended target range in case of a $\mathrm{VKA}^{918}$ (table 5).

\section{Stopping SAPT when starting OAC}

For patients who start with OAC and are already on SAPT, our experience is that the antiplatelet therapy is frequently not

\section{Main messages}

Treatment schedules for combined antithrombotic therapy in guidelines are complex, especially if a patient has several indications that require multiple antithrombotics. The risk of inadvertent prolonged continuation of antithrombotic therapy exists.

- An overview of the most common indications for mono, double and triple antithrombotic therapy; the preferred antithrombotic therapy; and the recommended duration of the therapy is provided in this article.

- With this information, healthcare providers can assess whether the prescribed antithrombotic therapy for a patient is adequate or whether the medication regimen should be adjusted.

- Antithrombotic therapy is a moving target. A lot of studies are now being conducted to find the optimal antithrombotic regimen for various indications.

\section{Current research questions}

To what extent is guideline-based combination antithrombotic therapy prescribed in daily practice?

- What is the optimal antithrombotic regimen when more than one antithrombotic agent is indicated?

- How can guideline-based prescription of antithrombotic therapy be improved in patients who use more than one antithrombotic agent? evaluated. If an OAC is started for a patient who uses SAPT, the rule of thumb is that the antiplatelet agent can be stopped, unless the patient has had an ACS or PCI in the past year, a recent CVA/ TIA, TAVI, valve surgery, carotid artery stenting or endovascular revascularisation.

Antiplatelet agent in double or triple therapy

Only clopidogrel and ASA should be combined with an OAC. P2Y12 inhibitors other than clopidogrel are not recommended, because of a higher bleeding risk.

Thrombosis prophylaxis combined with antithrombotics?

Patients who use SAPT or DAPT and have an indication for thrombosis prophylaxis should receive thrombosis prophylaxis as any other patient. Patients who use an OAC should not receive

\section{Self-Assessment questions}

1. A patient is diagnosed with a pulmonary embolism in August 2020. In 2015, this patient had a cerebrovascular accident.

What is the adequate antithrombotic therapy for this patient?

A. Clopidogrel plus acetylsalicylic acid.

B. Clopidogrel plus therapeutic anticoagulation therapy.

C. Therapeutic anticoagulation therapy.

D. Dipyridamole + therapeutic anticoagulation therapy.

2. A patient is admitted in August 2020 and is diagnosed with atrial fibrillation. In May 2020, he underwent percutaneous coronary intervention after a non-STEMI. What is the adequate antithrombotic therapy for this patient?

A. Therapeutic anticoagulation therapy and one antiplatelet agent.

B. Therapeutic anticoagulation therapy and two antiplatelet agents.

C. Therapeutic anticoagulation therapy.

D. Two antiplatelet agents (DAPT).

3. A patient receives a prophylactic dosage of a low-molecularweight heparin after surgery. The physician restarts the DOAC. When can the thrombosis prophylaxis be stopped?

A. Immediately.

B. After 1 day.

C. After 2 days.

D. When an adequate INR is reached

4. How much higher is the bleeding risk for a patient who uses the combination of a vitamin $\mathrm{K}$ antagonist plus a antiplatelet agent compared with a patient who uses only a vitamin $\mathrm{K}$ antagonist?
A. Same bleeding risk.
B. Two times as high.
C. Three times as high.
D. Four times as high.

5. A patient with atrial fibrillation had a STEMI and underwent a percutaneous coronary intervention. The cardiologist wants to start triple therapy. What is an adequate therapy?

A. Therapeutic anticoagulation therapy plus acetylsalicylic acid and clopidogrel.

B. Therapeutic anticoagulation therapy plus acetylsalicylic acid and ticagrelor.

C. Therapeutic anticoagulation therapy plus acetylsalicylic acid and prasugrel.

D. Therapeutic anticoagulation therapy plus acetylsalicylic acid and dipyridamole. 


\section{Key references}

1. Ruiz-Nodar JM, Marin F, Hurtado JA, et al. Anticoagulant and antiplatelet therapy use in 426 patients with atrial fibrillation undergoing percutaneous coronary intervention and stent implantation implications for bleeding risk and prognosis. J Am Coll Cardiol 2008;51:818-825.

2. Van Rein N, Heide-Jørgensen U, Lijfering WM. Major Bleeding Rates in Atrial Fibrillation Patients on Single, Dual, or Triple Antithrombotic Therapy, results from a nationwide Danish cohort study, Circulation 2019; 139:775-786.

3. Warlé-Van Herwaarden MF, Roukens M, Pop GAM. Adherence to guidelines for the prescribing of double and triple combinations of antithrombotic agents. Eur J Prev Cardiol 2014;21(2):231-43.

4. Leendertse AJ, Egberts AC, Stoker LJ. Frequency of and risk factors for preventable medication-related hospital admissions in the Netherlands. Arch Intern Med 2008 Sep 22;168(17):1890-6

5. Eikelboom JW, Connolly SJ, Bosch J, et al. Rivaroxaban with or without Aspirin in Stable Cardiovascular Disease. N Engl J Med 2017; 337: 1319-30

thrombosis prophylaxis. An exception are patients who have not yet reached a therapeutic INR when using a VKA.

\section{CONCLUSION}

Because of the complexity of guidelines for combined antithrombotic therapy, inadvertent prolonged continuation of antithrombotic therapy may occur. This article provides an overview of the indications for mono, double and triple antithrombotic therapy; the preferred antithrombotic therapy; the recommended duration of the therapy and future directions. With this overview, healthcare providers can evaluate the antithrombotic therapy for their patients. In case of deviations from the guidelines, the original prescriber should be contacted and the therapy should be evaluated. Our experience is that antiplatelet therapy can often be stopped, preventing patients from exposure to an unnecessarily high bleeding risk.

\section{Acknowledgements The authors would like to thank Dr. Erik G.J. Vermeulen for} his contribution to this article

Contributors Each author has substantially contributed to this manuscript. The final manuscript has been approved by all authors.

Funding The authors have not declared a specific grant for this research from any funding agency in the public, commercial or not-for-profit sectors.

Competing interests None declared.

Patient consent for publication Not required.

Provenance and peer review Not commissioned; externally peer reviewed.

ORCID iD

Matthijs L Becker http://orcid.org/0000-0003-0054-7498

\section{REFERENCES}

1 Nabauer M, Gerth A, Limbourg T, et al. The registry of the German competence network on atrial fibrillation: patient characteristics and initial management. Europace 2009;11:423-34.

2 Nieuwlaat R, Capucci A, Camm AJ, et al. Atrial fibrillation management: a prospective survey in ESC member countries: the Euro heart survey on atrial fibrillation. Eur Heart J 2005:26:2422-34

3 Ruiz-Nodar JM, Marín F, Hurtado JA, et al. Anticoagulant and antiplatelet therapy use in 426 patients with atrial fibrillation undergoing percutaneous coronary intervention and stent implantation implications for bleeding risk and prognosis. J Am Coll Cardiol 2008;51:818-25.
4 Hansen ML, Sørensen R, Clausen MT, et al. Risk of bleeding with single, dual, or triple therapy with warfarin, aspirin, and clopidogrel in patients with atrial fibrillation. Arch Intern Med 2010;170:1433-41.

5 Lamberts $\mathrm{M}$, Olesen JB, Ruwald MH, et al. Bleeding after initiation of multiple antithrombotic drugs, including triple therapy, in atrial fibrillation patients following myocardial infarction and coronary intervention: a nationwide cohort study. Circulation 2012;126:1185-93.

6 van Rein N, Heide-Jørgensen U, Lijfering WM, et al. Major bleeding rates in atrial fibrillation patients on single, dual, or triple antithrombotic therapy. Circulation 2019;139:775-86.

7 Dutch guideline cerebral infarction and cerebral hemorrhage (Herseninfarct en hersenbloeding). Available: https://richtlijnendatabase.nl/richtlijn/herseninfarct_en_ hersenbloeding/startpagina_herseninfarct-bloeding.html [Accessed 1 Jul 2019]

8 Montalescot G, Sechtem U, Achenbach S, et al. 2013 ESC guidelines on the management of stable coronary artery disease. Eur Heart J 2013;34:2949-3003.

9 Valgimigli M, Bueno H, Byrne RA, et al. 2017 ESC focused update on dual antiplatelet therapy in coronary artery disease developed in collaboration with EACTS. Eur J Cardio-thoracic Surg 2018;53:34-78.

10 Baumgartner H, Falk V, Bax JJ, et al. 2017 ESC/EACTS guidelines for the management of valvular heart disease. Eur Heart J 2017;38:2739-91.

11 Aboyans V, Ricco J-B, Bartelink M-LEL, et al. Editor's Choice - 2017 ESC Guidelines on the Diagnosis and Treatment of Peripheral Arterial Diseases, in collaboration with the European Society for Vascular Surgery (ESVS). Eur J Vasc Endovasc Surg 2018;55:305-68

12 Aboyans V, Ricco J-B, Bartelink M-LEL, et al. 2017 ESC guidelines on the diagnosis and treatment of peripheral arterial diseases, in collaboration with the European Society for vascular surgery (ESVS). Eur Heart J 2018;39:763-816.

13 Ricotta JJ, Aburahma A, Ascher E, et al. Updated Society for vascular surgery guidelines for management of extracranial carotid disease. J Vasc Surg 2011;54:e1-31.

14 Kirchhof P, Benussi S, Kotecha D, et al. 2016 ESC guidelines for the management of atrial fibrillation developed in collaboration with EACTS. Eur Heart $J$ 2016;37:2893-962.

15 Dutch guideline antithrombotic therapy (Antithrombotisch beleid). Available: https:// richtlijnendatabase.nl/richtlijn/antitrombotisch_beleid/antitrombotisch_beleid_-_ korte_beschrijving.html [Accessed 1 Jul 2019].

16 Konstantinides SV, Meyer G, Becattini C, et al. 2019 ESC guidelines for the diagnosis and management of acute pulmonary embolism developed in collaboration with the European respiratory Society (ERS). Eur Respir $J$ 2019;54:1901647.

17 , Windecker S, Kolh P, et al, Authors/Task Force members. 2014 ESC/EACTS Guidelines on myocardial revascularization: The Task Force on Myocardial Revascularization of the European Society of Cardiology (ESC) and the European Association for CardioThoracic Surgery (EACTS)Developed with the special contribution of the European Association of Percutaneous Cardiovascular Interventions (EAPCI). Eur Heart J 2014:35:2541-619.

18 Collet J-P, Thiele H, Barbato E, et al. Esc guidelines for the management of acute coronary syndromes in patients presenting without persistent ST-segment elevation. Eur Heart J 2020;2020:1-79.

19 Warlé-Van Herwaarden MF, Roukens M, Pop GAM, et al. Adherence to guidelines for the prescribing of double and triple combinations of antithrombotic agents. Eur J Prev Cardiol 2014:21:231-43.

20 Leendertse AJ, Egberts ACG, Stoker LJ, et al. Frequency of and risk factors for preventable medication-related hospital admissions in the Netherlands. Arch Intern Med 2008;168:1890-6.

21 Ashorobi D, Fernandez R. Thrombosis, Bookshelf PubMed NBK538430, 2019.

22 The Royal Dutch pharmacists association (Koninklijke Nederlandse Maatschappij TER bevordering Der Pharmacie) Informatorium Medicamentorum 2019 monograph antithrombotics. Available: https://kennisbank.knmp.nl/article/Informatorium Medicamentorum/G744.html\#G2033 [Accessed 2 Aug 2019].

23 Tomasdottir M, Friberg L, Hijazi Z, et al. Risk of ischemic stroke and utility of CHA DS -VASC score in women and men with atrial fibrillation. Clin Cardiol 2019;42:1003-9.

24 Klok FA, Huisman MV. How I assess and manage the risk of bleeding in patients treated for venous thromboembolism. Blood 2020;135:724-34.

25 Kang J, Park KW, Palmerini T, et al. Racial differences in Ischaemia/Bleeding risk tradeoff during anti-platelet therapy: individual patient level landmark meta-analysis from seven RCTs. Thromb Haemost 2019;119:149-62.

26 Levine GN, Jeong Y-H, Goto S, et al. Expert consensus document: world heart Federation expert consensus statement on antiplatelet therapy in East Asian patients with ACS or undergoing PCI. Nat Rev Cardiol 2014;11:597-606.

27 Inoue $\mathrm{H}$, Okumura K, Atarashi $\mathrm{H}$, et al. Target international normalized ratio values for preventing thromboembolic and hemorrhagic events in Japanese patients with nonvalvular atrial fibrillation: results of the J-RHYTHM registry. Circ J 2013;77:2264-70.

28 Shen AY-J, Yao JF, Brar SS, et al. Racial/Ethnic differences in the risk of intracranial hemorrhage among patients with atrial fibrillation. J Am Coll Cardiol 2007;50:309-15.

29 Kimura K, Kimura T, Ishihara M, et al. JCS 2018 guideline on diagnosis and treatment of acute coronary syndrome. Circ J 2019;83:1085-196. 
30 Mak K-H, Bhatt DL, Shao M, et al. Ethnic variation in adverse cardiovascular outcomes and bleeding complications in the clopidogrel for high atherothrombotic risk and ischemic stabilization, management, and avoidance (charisma) study. Am Heart $J$ 2009:157:658-65.

31 Eikelboom JW, Connolly SJ, Brueckmann M, et al. Dabigatran versus warfarin in patients with mechanical heart valves. N Eng/ J Med 2013;369:1206-14.

32 Eikelboom JW, Connolly SJ, Bosch J, et al. Rivaroxaban with or without aspirin in stable cardiovascular disease. N Eng/ J Med 2017:377:1319-30.

33 Mehran R, Baber U, Sharma SK, et al. Ticagrelor with or without aspirin in high-risk patients after $\mathrm{PCl}$. N Engl J Med 2019:1-10.

34 Claassens DMF, Vos GJA, Bergmeijer TO, et al. A Genotype-Guided Strategy for Oral P2Y Inhibitors in Primary PCI. N Eng/ J Med 2019;381:1621-31.

\section{Answers}

1. $C$

2. A

3. A

4. B

5. A 